1

\title{
Effect of Rooftop Exposure in Direct Sunlight on Conduit Ambient Temperatures
}

\author{
David Brender, Senior Member, IEEE, and Travis L. Lindsey
}

\begin{abstract}
4 Abstract-The interiors of electrical conduits located on 5 rooftops in full sunlight become considerably hotter than those 6 located in shaded areas. Differentials between these conduit inte7 rior temperatures and outside air temperatures (the latter always 8 measured in the shade) can easily reach $39{ }^{\circ} \mathrm{C}\left(70{ }^{\circ} \mathrm{F}\right)$ for con9 duits lying directly on a dark roof. As the height of the conduit 10 above the roof increases, this temperature differential decreases, 11 to perhaps $15{ }^{\circ} \mathrm{C}\left(27^{\circ} \mathrm{F}\right)$ at a height of $0.9 \mathrm{~m}(36$ in) above the 12 roof. Lighter-colored roofs, although they keep the interior of the 13 buildings cooler, actually reflect more heat onto conduits located 14 more than a few centimeters above the roof. This makes these 15 conduit interiors hotter as compared to conduits located above 16 dark-colored roofs. In practice, the actual temperatures inside 17 conduits are seldom taken into account when electrical ampacity 18 calculations are made. This can lead to serious overheating and 19 even failure of electrical cables inside the conduits.
\end{abstract}

20 Index Terms-Ampacity corrections, building wire, conduits, 21 derating, National Electrical Code (NEC), solar effects, Thermo22 plastic High Heat-resistant Nylon coated (THHN), wire and cable.

\section{INTRODUCTION}

24 HEN electrical conductors are placed in conduits lo25 cated in sunlight, the interiors of those conduits can 26 reach quite high temperatures. The temperature of the air inside 27 a conduit is the "ambient temperature" that should be used 28 for sizing the cables. In practice, temperature corrections are 29 seldom made, due in part to a lack of knowledge on what those 30 ambient temperatures actually are.

\section{A. Ambient Temperature Corrections}

32 As the temperature of a metallic conductor increases, its 33 ampacity, or current-carrying capacity, decreases due to the 34 accompanying rise in electrical resistance. Certain tables and 35 equations in the U.S. National Electrical Code (NEC)36 particularly Table 310-16-are intended to make the necessary

Paper ICPSD-06-36, presented at the 2006 Industry Applications Society Annual Meeting, Tampa, FL, October 8-12, and approved for publication in the IEEE TRANSACTIONS ON INDUSTRY APPLICATIONS by the Power Systems Engineering Committee of the IEEE Industry Applications Society. Manuscript submitted for review October 15, 2006 and released for publication March 6, 2008. This work was supported by the Copper Development Association, Inc.

D. Brender is with the Copper Development Association, Inc., New York, NY 10016 USA (e-mail: dbrender@cda.copper.org).

T. L. Lindsey is with TLC Consulting Services, Las Vegas, NV 89129 USA (e-mail: traviscl@msn.com).

Color versions of one or more of the figures in this paper are available online at http://ieeexplore.ieee.org

Digital Object Identifier 10.1109/TIA.2008.2006301 ampacity corrections for elevated temperatures, known as der- 37 ating the cable [1]. These tables take into account the additional 38 $I^{2} R$ heat added to the conductor by the current flowing through 39 it. A danger point is reached when the ambient plus the $I^{2} R 40$ heating exceeds the temperature rating of the cable insulation 41 or other covering, which is often $90^{\circ} \mathrm{C}\left(194^{\circ} \mathrm{F}\right)$.

Conduits in direct sunlight on the flat rooftops of industrial 43 and commercial buildings are a common occurrence in many 44 areas. Since many variables might influence conduit temper- 45 atures, such as the color and texture of the roof, how high 46 above the roof the conduit is placed, the type of conduit, the 47 geographical location of the building in question, and the time 48 of year, research was needed to determine the influence of these 49 factors.

\section{B. Outdoor Temperatures}

51

Since the main purpose of this research was to determine 52 the temperature adjustment that needs to be added to the ex- 53 pected outdoor temperature for a given location, it is important 54 to use an accepted number for the outdoor air temperature 55 itself.

Fortunately, the American Society of Heating, Refrigerat- 57 ing and Air-Conditioning Engineers, Inc. (ASHRAE) deals 58 with outdoor temperatures in order to design air-conditioning 59 and heating systems [2]. An ASHRAE weather database for 60 753 locations in the USA, and 4422 worldwide, includes sum- 61 mer design temperatures. The temperature data are based on 62 30 years (1972-2001) of hourly readings from weather stations 63 of the National Climatic Data Center, a subsidiary of the 64 National Oceanic and Atmospheric Administration, and both 65 are part of the U.S. Department of Commerce [3].

It is quite important to use appropriate design temperatures to 67 properly size a building's air-conditioning system. Undersizing 68 the system will not provide sufficient air conditioning on hot 69 days, while oversizing causes the system to run too little, 70 resulting in insufficient dehumidification as well as wasted 71 energy when it does run.

However, the consequences of improperly sized air condi- 73 tioning are only poor economics or uncomfortable days in the 74 summer. The consequences of an undersized electrical distrib- 75 ution system may be more severe-failure of cable insulation 76 leading to shorts or other problems. Note that these failures 77 may occur at currents below those protected by circuit breakers 78 when derating has not been done, removing any automatic 79 protection afforded by the breaker.

Table I shows design temperatures for 16 locations from 81 the ASHRAE database. Since hottest temperatures almost 82 
TABLE I

Outdoor Air Temperatures For SElected U.S. Cities

\begin{tabular}{|c|c|c|c|}
\hline City & $\begin{array}{c}2 \% \text { Design } \\
\underline{\text { Temp. }{ }^{\circ} \mathrm{C}}\end{array}$ & $\begin{array}{l}1 \% \text { Design } \\
\underline{\text { Temp. }{ }^{\circ} \mathrm{C}}\end{array}$ & $\begin{array}{c}\operatorname{Max} \\
\text { Temp. }{ }^{o} \mathrm{C} * \\
\end{array}$ \\
\hline Phoenix, AZ & 43 & 44 & 49 \\
\hline Las Vegas, NV & 42 & 43 & 48 \\
\hline Wichita, KS & 38 & 39 & 45 \\
\hline Houston, TX & 36 & 36 & 42 \\
\hline Atlanta, GA & 34 & 35 & 41 \\
\hline New Orleans, LA & 34 & 35 & 39 \\
\hline Denver, $\mathrm{CO}$ & 34 & 35 & 41 \\
\hline Miami, FL & 33 & 33 & 38 \\
\hline New York, NY & 33 & 34 & 40 \\
\hline Chicago, IL & 33 & 34 & 40 \\
\hline Minneapolis/St. Paul, MN & 32 & 33 & 41 \\
\hline Boston, MA & 32 & 33 & 40 \\
\hline Pittsburgh, PA & 31 & 32 & 39 \\
\hline Los Angeles, CA & 26 & 27 & 42 \\
\hline San Francisco, CA & 25 & 28 & 40 \\
\hline Fairbanks, AK & 24 & 28 & 36 \\
\hline
\end{tabular}

83 everywhere in the northern hemisphere can be found between 84 June 1 and August 31, those three months are considered. Thus, 85 the three months constitute a total of 2208 hourly readings for 86 each year.

87 The 2\% readings in Table I represent a percentile approach. 88 Thus, in a typical year, it would be expected that 44 of the 2208 89 readings for Phoenix would be above $43{ }^{\circ} \mathrm{C}\left(110^{\circ} \mathrm{F}\right)$. A more 90 severe design criterion sometimes used is $1 \%$, in which case 9122 readings in Phoenix should be above $44{ }^{\circ} \mathrm{C}\left(111^{\circ} \mathrm{F}\right)$. As a 92 comparison, the highest temperatures for the last 50 years are 93 also shown. In the case of Phoenix, it is $49^{\circ} \mathrm{C}\left(121^{\circ} \mathrm{F}\right)$.

94 It is recommended that the $2 \%$ criterion be used to determine 95 the applicable summer outdoor temperature for a given location 96 for design purposes. The average differential between the $2 \%$ 97 level and the maximum is about $8{ }^{\circ} \mathrm{C}\left(15^{\circ} \mathrm{F}\right)$, with Miami 98 the lowest at $5{ }^{\circ} \mathrm{C}\left(9^{\circ} \mathrm{F}\right)$. However, because of local climate 99 peculiarities, for Los Angeles it is a much larger $16{ }^{\circ} \mathrm{C}\left(29^{\circ} \mathrm{F}\right)$ 100 and for San Francisco $15^{\circ} \mathrm{C}\left(27^{\circ} \mathrm{F}\right)$. For those cities, it may 101 well be prudent to use a higher design temperature than the $2 \%$ 102 level.

103 Others have argued that absolute maximum temperatures on 104 record for a given region should be used, because of the serious 105 consequences of cable failure. The counterarguments to this are 106 threefold: 1) The economic consequences of sizing cable to a 107 once-in-a-lifetime occurrence could be severe; 2 ) the ampacity 108 tables such as NEC Table 310-16 supposedly already have 109 some safety factor built in; and 3) since derating for overheating
TABLE II

Solar Radiation fOR SElected U.S. Cities

\begin{tabular}{|c|c|c|c|}
\hline Location & $\begin{array}{c}\text { June } \\
\text { Global Horizontal } \\
\text { Radiation } \\
\text { cal/cm }{ }^{2}-d a y \\
\end{array}$ & $\begin{array}{c}\text { June } \\
\text { Clear Air } \\
\text { Radiation } \\
\text { cal/cm }{ }^{2}-d a y \\
\end{array}$ & $\begin{array}{c}\text { March } \\
\text { Clear Air } \\
\text { Radiation } \\
\text { cal/cm }{ }^{2}-d a y\end{array}$ \\
\hline Phoenix, AZ & 719 & 749 & 540 \\
\hline Las Vegas, NV & 719 & 759 & 529 \\
\hline Wichita, KS & 575 & 722 & 496 \\
\hline Houston, TX & 518 & 697 & 545 \\
\hline Atlanta. GA & 553 & 703 & 524 \\
\hline New Orleans, LA & 526 & 689 & 540 \\
\hline Denver, CO & 586 & 751 & 496 \\
\hline Miami, FL & 480 & 681 & 570 \\
\hline New York, NY & 526 & 700 & 453 \\
\hline Chicago, IL & 540 & 705 & 445 \\
\hline Mpls/St. Paul, MN & 526 & 719 & 434 \\
\hline Boston, MA & 526 & 700 & 437 \\
\hline Pittsburgh, PA & 521 & 705 & 456 \\
\hline Los Angeles, CA & 567 & 708 & 505 \\
\hline San Francisco, CA & 616 & 716 & 477 \\
\hline Fairbanks, AK & 483 & 678 & 220 \\
\hline
\end{tabular}

in conduits in direct sunlight is, by and large, not being done 110 now, any improvement is better than the status quo.

It is likely that the design outdoor temperature for a given 112 area, to which the appropriate temperature adjustment identified 113 later in this paper should be added, will be decided at the local 114 level. ASHRAE data are available for all major population 115 centers in the USA, and temperatures can be estimated in all 116 other locations based on nearby data.

\section{Solar Radiation}

118

The work reported on in this paper was carried out in Las 119 Vegas, NV. Since Las Vegas is one of the hotter sites listed in 120 Table I, it has been suggested that these data are not typical of 121 other cooler locations.

In fact, Las Vegas is a particularly good test site because 123 of its high number of clear days per year, and broad range of 124 solar radiation intensities in different seasons, allow for good 125 correlation of data with cities throughout the USA.

126

The relevant climatic property is solar radiation. Data are 127 available for various orientations of solar collectors for various 128 stations from the National Renewable Energy Laboratories [4]. 129 Collectors are oriented at various angles to the sun but, since 130 industrial and commercial roofs are nearly flat, the relevant 131 orientation for the collector for this purpose is horizontal. $\quad 132$

Table II shows solar radiation data for the same cities, in 133 the same order, as shown in Table I. Actual data for June are 134 shown, averaged over a 30-year period, followed by the "clear- 135 air" values for June and for March as a comparison, when the 136 sun is lower in the sky. All units are in calories per horizontal 137 square centimeter per day. 


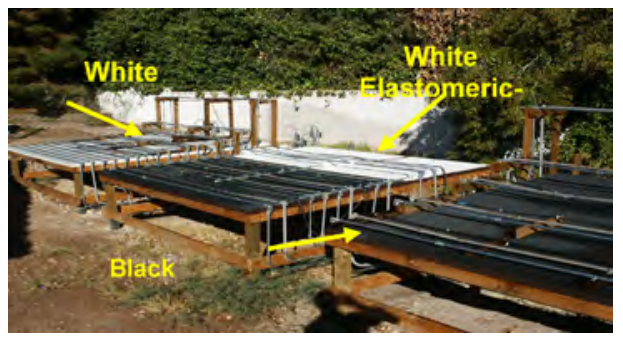

Fig. 1. Roof surfaces cover range of reflectivity from very white to black.

139 Examination of Table II shows that the variation between 140 U.S. cities on a clear day in June, when the sun is highest in the 141 sky, is remarkably small (759 for Las Vegas, 678 for Fairbanks, 142 AK). During other months, the differences are much greater. 143 For March, for instance, Las Vegas measures 529 on a clear 144 day, while Fairbanks is only 220. Second, Las Vegas in March 145 has a much lower value than any city in the table in June. This 146 tends to support the conclusion that tests run in Las Vegas in 147 the spring involve less heating from solar radiation than many 148 other cities in the summer on a clear day.

149 Of course, not all days are clear, and this is shown by the 150 actual June readings versus the clear air reading for cities like 151 Miami (480 versus a theoretical 681). Nevertheless, all cities 152 have many clear sunny days during the summer months, and 153 proper design must account for this.

154 1) Related Design Applications: Formulas exist in other 155 electrical applications, such as in the design of overhead cable 156 to IEEE standards, to use solar radiation data to determine am157 pacity [5], [6]. These standards and methodologies all assume 158 constant solar radiation conditions anywhere in the USA. One 159 such paper [7] states that the use of $900 \mathrm{~W} / \mathrm{m}^{2}$ “. . . is typical 160 of conditions that exist on a bright, sunny mid-summer day 161 throughout most of the United States. .."1

162 2) Wind: One concern that has been expressed to the use 163 of data derived in Las Vegas for other locations was that some 164 locations experience significant winds a good percentage of the 165 time. However, the wind is not always blowing on a hot day in 166 any location, so this argument should be rejected. The IEEE 167 working group for Standard 738, in fact, recommended that 168 wind not be taken into account in designing overhead cable, 169 because of its sporadic nature [5].

\section{EXPERIMENTAL PROCEDURE}

171 The experiments are being conducted at a Las Vegas, NV, 172 test site consisting of three simulated roof sections (Fig. 1). 173 The sections were covered with three types of roofing surfaces: 174 black mineral roll roofing, white mineral roll roofing, and 175 mineral roll roofing painted with a white elastomeric coating. 176 The latter is a brighter, more reflective roof surface than the 177 uncoated white roofing.

178 Three-quarter-inch electrical metallic tubing (EMT) was 179 used as conduit in the experiments. Each contains three AWG

${ }^{1}$ The $900 \mathrm{~W} / \mathrm{m}^{2}$ converts directly to $77 \mathrm{cal} / \mathrm{cm}^{2} \cdot \mathrm{h}$. Clear-air June data for most of the cities in Table II are about $700 \mathrm{cal} / \mathrm{cm}^{2}$. day, or about $9 \mathrm{~h}$ at that high level of intensity. This comparison confirms that [7] and the NREL data [4] are consistent.

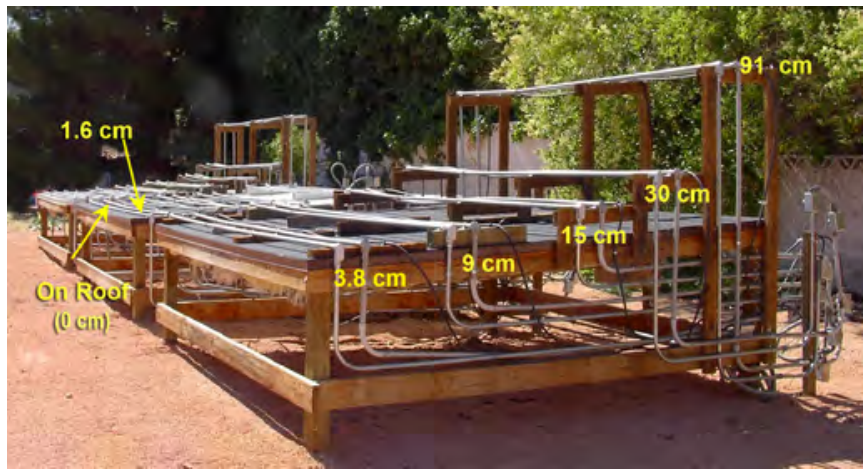

Fig. 2. Conductors situated in conduits lying on roof surface and incrementally above roof to $91 \mathrm{~cm}$.

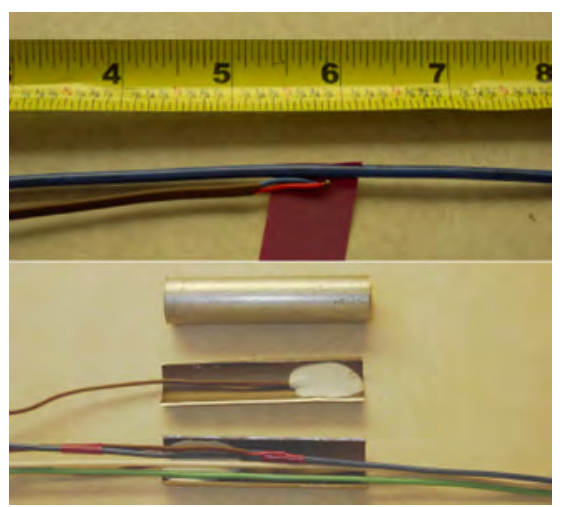

Fig. 3. (Top) Copper-constantan thermocouple being applied to outer insulation of THHN conductor. (Bottom) Cutaway of EMT conduit showing placement of thermocouples on phase conductor and on top and bottom inside surface of conduit.

12 Thermoplastic High Heat-resistant Nylon coated (THHN) 180 copper conductors - one with either black, blue, or red insula- 181 tion, one with white insulation, and one with green insulation. 182 The conduits were arranged at seven different heights above 183 the black and white roll roofing (Fig. 2). These heights were 184 directly on roof, on struts $1.6 \mathrm{~cm}$ (5/8 in) above the roof, and 185 at heights of $3.8 \mathrm{~cm}(1-1 / 2 \mathrm{in}), 9 \mathrm{~cm}$ (3-1/2 in), $15 \mathrm{~cm}$ (6 in), 186 $30 \mathrm{~cm}$ (12 in), and $91 \mathrm{~cm}$ (36 in). The white elastomeric-coated 187 roof had samples only at the 9 -cm height.

188

Experiments were also conducted with rigid nonmetallic 189 conduit (RNC) and earlier with a small number of intermediate 190 metallic conduit. The RNC tended to run a bit hotter than EMT 191 because its surface darkened considerably over the course of the 192 experiment. Since all the conduits showed the same qualitative 193 effects, for simplicity, only the results of the EMT experiments 194 are reported here.

195

All the conductors were electrically unloaded. Type T 196 copper-constantan thermocouples were used as temperature 197 sensors. Fig. 3(a) shows a thermocouple ready to be taped to 198 the insulation of a length of THHN phase conductor. Fig. 3(b) 199 shows a cutaway of a conduit section with a phase conductor 200 with sensor attached, a white neutral, and a green grounding 201 conductor. Sensors attached to the inside bottom and top of the 202 conduit itself are also shown.

The sensors were positioned at the center of each length of 204 conduit, as shown in Fig. 2. These sensors were then routed 205 
TABLE III

TEMPERATURE RISE InSIDE EMT CONDUIT OVER BLACK ROOF From SOLAR RADIATION

\begin{tabular}{|c|c|c|c|c|c|c|c|c|c|c|}
\hline Example: & 1 & 2 & 3 & 4 & 5 & 6 & 7 & 8 & 9 & 10 \\
\hline Outdoor Temp, ${ }^{\circ} \mathrm{C}$ : & 14 & 16 & 20 & 22 & 24 & 30 & 36 & 38 & 43 & 47 \\
\hline Day of reading: & 31-Jan & 31-Mar & 22-Jan & 14-Apr & 15-Apr & 12-Jun & 21-May & 22-May & $16-J_{u} 1$ & 17-Jul \\
\hline Time of reading: & $11: 30$ & $12: 00$ & $12: 15$ & $1: 00$ & $1: 00$ & $12: 00$ & $12: 30$ & $2: 00$ & $12: 45$ & $2: 15$ \\
\hline \multicolumn{11}{|c|}{ Temperature Differentials, " $C^{*}$} \\
\hline ON roof surface & 32 & 36 & 29 & 39 & 35 & 36 & 39 & 36 & 36 & 36 \\
\hline $1.6 \mathrm{~cm}$ above roof & 23 & 26 & 21 & 27 & 24 & 25 & 27 & 26 & 26 & 24 \\
\hline $3.8 \mathrm{~cm}$ above roof & 19 & 21 & 15 & 23 & 18 & 20 & 21 & 18 & 21 & 20 \\
\hline $9 \mathrm{~cm}$ above roof & 18 & 19 & 14 & 21 & 17 & 19 & 21 & 18 & 20 & 18 \\
\hline $15 \mathrm{~cm}$ above roof & 17 & 18 & 13 & 19 & 16 & 17 & 18 & 16 & 17 & 14 \\
\hline $30 \mathrm{~cm}$ above roof & 16 & 17 & 11 & 17 & 14 & 16 & 17 & 15 & 16 & 13 \\
\hline $91 \mathrm{~cm}$ above roof & 13 & 14 & 10 & 15 & 13 & 14 & 14 & 13 & 14 & 12 \\
\hline
\end{tabular}

"Sample of midday temperature differentials—between air in conduit and outside temperature; 3/4" EMT, AWG12; untoaded, as measured on insulation.

206 back to a multiplex unit and computer located in a climate207 controlled building adjacent to the experiment. Temperatures 208 were recorded at 1-min intervals throughout the day and night. 209 However, 15-min averages were calculated, and only those data 210 were permanently retained and used.

211 For comparison purposes, temperatures were also measured 212 on the top and bottom inside surfaces of some conduits 213 [Fig. 3(b)] and, in some samples not containing conductors, in 214 the free air space in the center of the conduit. All temperature 215 readings in these instances were within a degree or two of 216 each other and of the temperature on the sensor attached to 217 the conductor. Therefore, the temperature readings on the phase 218 conductors were accepted as an accurate representation of the 219 ambient temperature in the conduit. Of course, this would 220 not have been the case had the conductors been electrically 221 loaded.

222 Outdoor temperatures were measured using a standard six223 plate solar radiation shield containing multiple thermocouple 224 sensors installed in a housing. The temperatures of the various 225 thermocouples were averaged.

226 The experiment was carried out between May 2004 and 227 August 2005. Further details of the experimental procedure are 228 available on request.

\section{RESULTS}

230 Note that the rooftop data reported in this paper in most cases 231 represent temperature differentials, not actual temperatures in232 side the conduits. The differential is derived by subtracting the 233 measured outdoor temperature from the measured temperature 234 inside the conduit for each sample for each time recorded 235 (to avoid any confusion between temperature differentials and 236 measured temperatures, note that conversions from ${ }^{\circ} \mathrm{C}$ to ${ }^{\circ} \mathrm{F}$ are 237 a straight $5 / 9$ ratio for temperature differentials, not involving 238 the $\pm 32^{\circ}$ used when converting measured temperatures).

239 The database was first "cleaned" by eliminating all outdoor 240 temperatures under $21^{\circ} \mathrm{C}\left(70{ }^{\circ} \mathrm{F}\right)$, since the experiment is 241 intended to measure effects at high summer temperatures.
Next, cloudy periods were eliminated. These could be easily 242 identified by sudden drops in the temperature differentials from 243 one 15-min period to the next. Again, this is justified since the 244 purpose of the experiment was to study only the effects of direct 245 sunlight on temperatures inside conduits. Since only about 17\% 246 of the data were eliminated by this latter exercise, it further 247 illustrates the advantage of using Las Vegas as a test site. A 248 nondesert location would have produced far fewer usable data 249 points.

\section{A. Solar Effect}

During the time of the experiment, outdoor temperatures 252 ranged from $10{ }^{\circ} \mathrm{C}$ to $47{ }^{\circ} \mathrm{C}\left(50{ }^{\circ} \mathrm{F}\right.$ to $\left.116{ }^{\circ} \mathrm{F}\right)$. Under all 253 conditions tested, temperatures inside EMT conduits in direct 254 sunlight are considerably higher than outdoor temperatures. To 255 illustrate this, a random compilation of midday temperature-rise 256 data under a wide variety of outdoor temperatures and seasons 257 is shown in Table III for a black roof. In all cases, the sun was 258 unobscured by clouds when the readings were taken.

259

The temperature-differential data show a high degree of 260 consistency at the different times of year, whether the outdoor 261 temperature is $14{ }^{\circ} \mathrm{C}$ or $47^{\circ} \mathrm{C}$. Temperature differentials on the 262 roof surface are all in the range of $29{ }^{\circ} \mathrm{C}-39{ }^{\circ} \mathrm{C}$, and even at 263 $91 \mathrm{~cm}$ above the roof the range is narrow, from $10{ }^{\circ} \mathrm{C}$ to $15^{\circ} \mathrm{C}$. 264

\section{B. Statistical Basis}

The statistical approach used by ASHRAE to determine de- 266 sign temperatures would seem to apply as well to temperature- 267 rise data derived in this experiment. However, the $2 \%$ figure 268 used for the outdoor temperature would seem to be a bit "tight" 269 for this data set. The reasons are the following: 1) The data from 270 this experiment are focused only on the midday period from 271 11 A.M. to 3 P.M. (daylight savings time), as opposed to all 272 $24 \mathrm{~h}$ of the day in the ASHRAE database; 2) only times when 273 the sun is unobscured are considered; and 3) the database is 274 considerably smaller than the 30-year ASHRAE temperature 275 
TABLE IV

Temperature Rises Inside EMT Conduits in Full Sunlight at Various Heights Above Roof, Based on Percentile of Reading

\begin{tabular}{|c|c|c|c|c|c|c|c|}
\hline \multirow[b]{2}{*}{ Percentile** } & \multicolumn{7}{|c|}{ Temperature Rise Above Outdoor Temperature, ${ }^{\circ} \mathrm{C}^{*}$} \\
\hline & On Roof & $1.6 \mathrm{~cm}$ above & $3.8 \mathrm{~cm}$ above & $9 \mathrm{~cm}$ above & $15 \mathrm{~cm}$ above & $30 \mathrm{~cm}$ above & $91 \mathrm{~cm}$ above \\
\hline $0 \%(\max )$. & 40 & 27 & 26 & 24 & 23 & 21 & 17 \\
\hline $2 \%$ & 38 & 26 & 25 & 23 & 22 & 20 & 16 \\
\hline $5 \%$ & 37 & 26 & 25 & 22 & 21 & 19 & 15 \\
\hline $50 \%$ (median) & 34 & 24 & 22 & 20 & 18 & 16 & 14 \\
\hline
\end{tabular}

* Average values for light and dark roofs.

*** Measured from top.

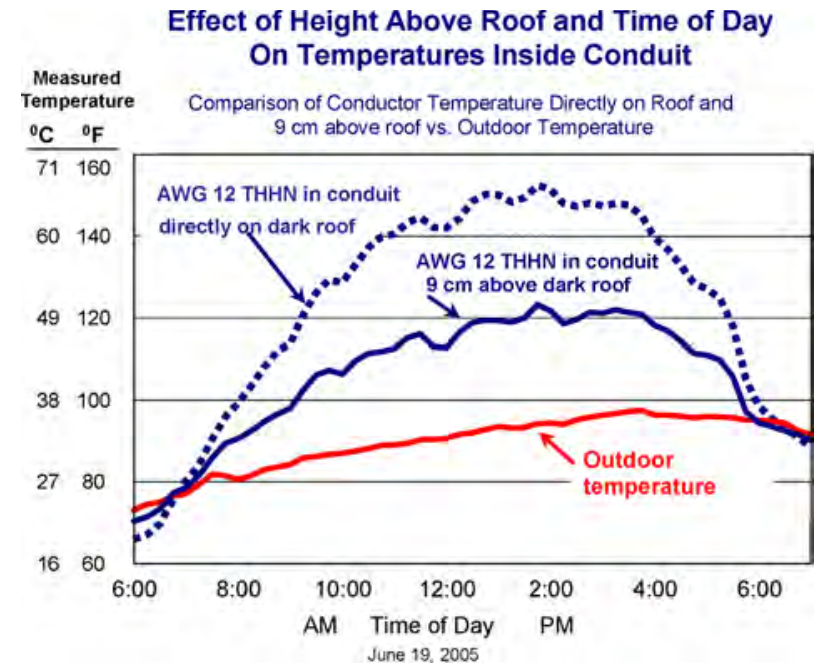

Fig. 4. Effect of height above roof and time of day on temperatures inside conduit.

276 database. For these reasons, a $10 \%$ cutoff point is suggested, 277 and the data that follow are at this level.

278 Table IV illustrates temperature rises at various heights above 279 the roofs at different percentile levels, from $0 \%$ (highest number 280 in data set) to $2 \%, 5 \%$, the recommended $10 \%$, and, finally, $28150 \%$, the median figure. The 10th percentile in all cases is 282 roughly halfway between the highest number and the median, 283 and so seems a reasonable compromise. Please note that all data 284 to follow represent the 10th percentile measured from the top 285 (hot) end.

\section{C. Distance Above Roof}

287 The temperature rise within a rooftop conduit in full sun 288 decreases as the distance above the roof surface increases. The 289 most dramatic temperature increase takes place for conduits 290 lying directly on the roof, which had solar increases as high as $29140^{\circ} \mathrm{C}$ (Table IV). The 10th percentile used for design purposes 292 is $37^{\circ} \mathrm{C}\left(67^{\circ} \mathrm{F}\right)$.

293 As the height above the roof increases to the $1.6 \mathrm{~cm}$ of a 294 standard type of roof strut, the temperature rise drops by $11^{\circ} \mathrm{C}$ 295 to $26{ }^{\circ} \mathrm{C}$ above the outdoor temperature. For $9 \mathrm{~cm}($ a $2 \times 4$ 296 placed on edge, which is also commonly used), the differential
Effect of Roof Color and Height Above Roof on Temperatures Inside Conduit

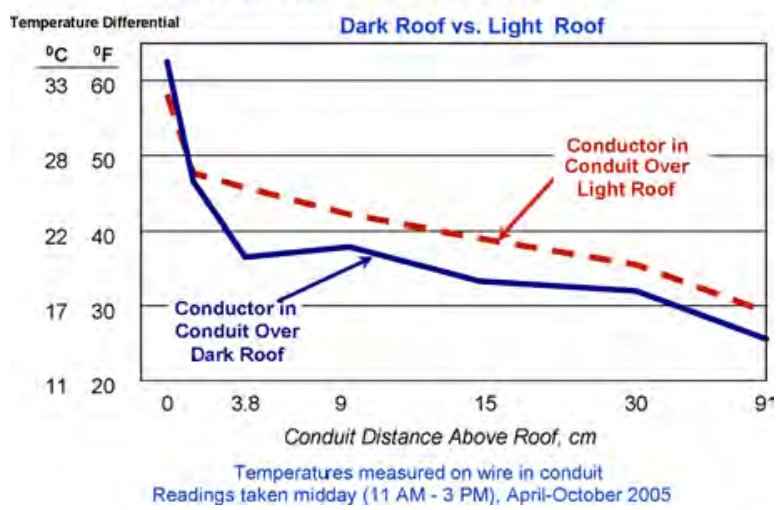

Fig. 5. Effect of roof color and height above roof on temperatures inside conduit.

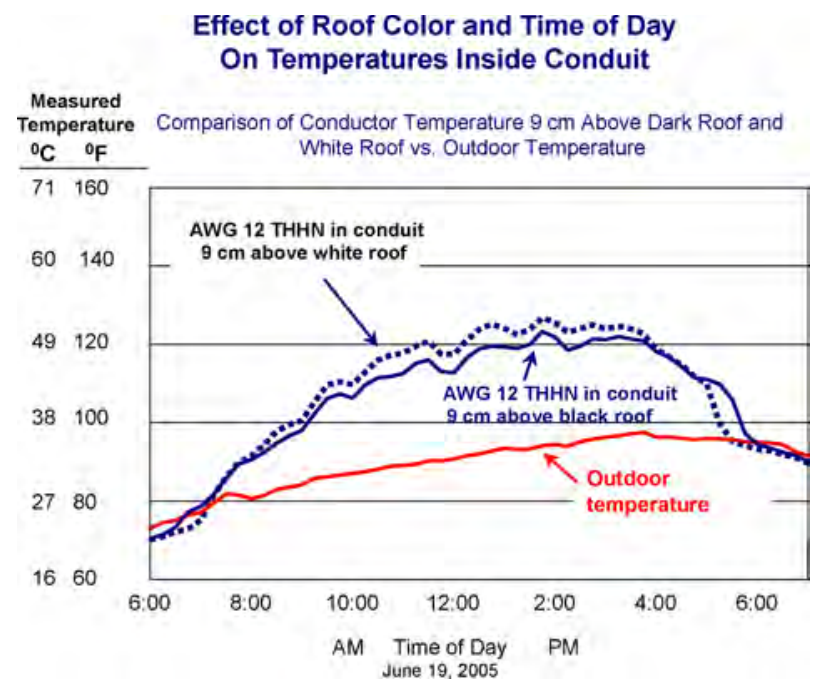

Fig. 6. Effect of roof color and time of day on temperatures inside conduit.

compared to outdoor temperature is $22{ }^{\circ} \mathrm{C}$. Moreover, for the 297 highest elevation above the roof surface-91 cm-the differen- 298 tial is still $15^{\circ} \mathrm{C}\left(27^{\circ} \mathrm{F}\right)$.

Fig. 4 shows this phenomenon from another perspective 300 time of day. The change in measured temperature (not the 301 temperature differential) inside conduits over the course of a 302 
TABLE V

Temperature Rises Inside EMT Conduits in Full Sunlight at Various Heights Above Roof, BASEd on OUtdoor Temperature RANGE-10th PERCENTILE

\begin{tabular}{|c|c|c|c|c|c|c|c|c|}
\hline & & \multicolumn{7}{|c|}{ Temperature Rise Above Outdoor Temperature, ${ }^{0} \mathrm{C} *$} \\
\hline \multicolumn{2}{|c|}{ Outdoor Temperature } & & $1.6 \mathrm{~cm}$ above & $3.8 \mathrm{~cm}$ above & $9 \mathrm{~cm}$ above & $15 \mathrm{~cm}$ above & $30 \mathrm{~cm}$ above & $91 \mathrm{~cm}$ above \\
\hline${ }^{\prime \prime C}$ & ${ }^{n} \mathbf{F}$ & On Roof & & & & & & \\
\hline $21-26.5$ & $70-79.9$ & 37 & 26 & 24 & 22 & 21 & 18 & 15 \\
\hline $27-31.5$ & $80-89.9$ & 36 & 26 & 24 & 22 & 21 & 19 & 15 \\
\hline $32-37.5$ & $90-99.9$ & 37 & 26 & 24 & 21 & 20 & 18 & 15 \\
\hline$\geq 38$ & $\geq 100$ & 37 & 25 & 24 & 21 & 20 & 17 & 14 \\
\hline All temps & All temps & 37 & 26 & 24 & 22 & 20 & 18 & 15 \\
\hline
\end{tabular}

303 midsummer day is shown for two heights above the dark roof: $3049 \mathrm{~cm}$ and directly on the roof. For comparison, the outdoor 305 temperature is also shown. The gap between outdoor and 306 conduit temperatures starts at about 7 A.M. and builds quickly 307 by mid-morning. The differential is wide until after 4 P.M., 308 disappearing at about 7 P.M. This figure is shown to illustrate 309 that heating inside conduits is not limited only to high noon.

310 Because of the large difference in temperature rises depend311 ing on height above roof, this paper's recommendations suggest 312 that electrical designers take this factor into account.

\section{D. Roof Color}

314 Temperatures inside conduits over dark-colored roof surfaces 315 are higher than over light-colored surfaces if the conduits are 316 on or quite close to the roof, as shown in Fig. 5. However, 317 for distances greater than about 2 or $3 \mathrm{~cm}$ above the surface, 318 and continuing until at least $91 \mathrm{~cm}$, conduits over light surfaces 319 are hotter, due to the higher reflection of heat from the light 320 surface.

321 Fig. 6 shows this from the time-of-day perspective, using data 322 from the same day, as shown in Fig. 4. Again, the temperature 323 differential between outdoor temperature and temperatures in324 side conduits $9 \mathrm{~cm}$ above the roofs rises rapidly and stays high 325 throughout the day.

326 However, the relatively small gap between the upper lines 327 does not lead to the conclusion that any distinction be made 328 between roof colors for design purposes.

329 It should be noted that, particularly in hotter climates, light330 colored roof surfaces are recommended because of their ability 331 to keep a building's interior cooler [8]. This has the unintended 332 effect of increasing the temperature burden on conductors in 333 rooftop conduits in locations with the most severe summer 334 temperatures.

335 The combination of the two previous factors-distance above 336 roof and roof color-means that temperatures inside conduits 337 over light-colored roofs are consistently higher than over dark338 colored roofs, from about 2 to $91 \mathrm{~cm}$ above the roof.

\section{E. Outdoor Temperature Range}

340 Table $\mathrm{V}$ shows the data arranged by outdoor temperatures. 341 It shows a remarkable consistency in temperature rise, no
TABLE VI

RECOMMENDED AdJUSTMENTS (ADDITIONS) TO OUTDOOR TEMPERATURES TO DETERMINE AMBIENT TEMPERATURES INSIDE CONDUITS

\begin{tabular}{lcc}
\hline Distance Above Roof & \multicolumn{2}{c}{$\begin{array}{c}\text { Temperature } \\
\text { Adjustments }\end{array}$} \\
\hline On roof, up to and including $1.3 \mathrm{~cm}$. above roof & ${ }^{\circ} \mathbf{C}$ & ${ }^{\circ} \mathbf{F}$ \\
Above $1.3 \mathrm{~cm}$, up to and including $9 \mathrm{~cm}$. above roof & 33 & 60 \\
Above $9 \mathrm{~cm}$, up to and including $30 \mathrm{~cm}$. above roof & 17 & 30 \\
Above $30 \mathrm{~cm}$, up to and including $91 \mathrm{~cm}$. above roof & 14 & 25 \\
\hline
\end{tabular}

matter what the outdoor temperature is, over the full range 342 studied. In fact, the data indicate that outdoor temperature is 343 a minor factor in determining what temperature adjustment to 344 make to arrive at ambient temperature inside a conduit in full 345 sunlight.

\section{CONClusion And ReCOMmendations}

Attention should be paid by those designing electrical sys- 348 tems for industrial, commercial, and other flat-roofed buildings 349 to potential problems caused by the presence of conductors 350 inside conduits located outside in direct sunlight.

The air inside conduits in direct sunlight gets significantly 352 hotter than the surrounding air, and designers need to make 353 appropriate ampacity corrections. Although light-colored roofs 354 reflect more heat than dark roofs and keep their buildings 355 cooler, some of the heat is reflected to the conduit above the 356 roof, making the air in the conduit generally hotter. Data from 357 the experiment suggest that temperature rises in conduits over 358 roofs of any color can be considered roughly equivalent, so 359 there is no need to make distinctions for design purposes. $\quad 360$

Neither is there a need to make distinctions based on the level 361 of outdoor temperatures. Temperature rises are remarkably con- 362 stant no matter what the outdoor temperature is during summer 363 conditions.

It is suggested that the temperature adjustments shown in 365 Table VI be used to convert outdoor design temperatures for 366 a given area to temperatures inside conduits in direct sunlight. 367 


\section{REFERENCES}

369 [1] National Fire Protection Association, National Electrical Code, NFPA 70, $370 \quad 2005.772 \mathrm{pp}$.

371 [2] American Society of Heating, Refrigerating and Air-Conditioning Engi372 neers, Inc., ASHRAE Handbook-Fundamentals, 2005. including world373 wide data tables.

374 [3] National Climatic Data Center, National Environmental Satellite, Data and 375 Information Services. including worldwide data tables.

376 [4] National Renewable Energy Laboratories (NREL), Solar Radiation Data 377 Manual for Buildings. including worldwide data tables.

378 [5] IEEE Standard for Calculation of Bare Overhead Conductor Temperature 379 and Ampacity Under Steady-State Conditions, ANSI/IEEE Std. 738-1986. 380 [6] IEEE Standard Power Cable Ampacity Tables, IEEE Std. 835-1994.

381 [7] R. A. Hartlein and W. Z. Black, "Ampacity of electric power cables in 382 vertical protective risers," in Proc. IEEE PES Summer Meeting, 1982.

383 [8] D. S. Parker, J. K. Sonne, and J. R. Sherwin, Flexible Roofing Facility: 2004

384 Summer Test Results. Cocoa, FL: Florida Solar Energy Center, Jul. 2005,

385 p. 23. prepared for U.S. Department of Energy Building Technologies 386 Program.
David Brender (S'73-M'79-SM'02)

$387 \quad \mathbf{A Q 3}$

He is currently with the Copper Development Association, Inc. (CDA), 388 New York, NY, as a National Program Manager. He worked in the utility 389 and electrical fields for 40 years. His current duties include management 390 of electrical programs at CDA, including energy efficiency, power quality, 391 research, code, and building wire issues. He sits on Panel 5 of the National 392 Electrical Code.

Travis L. Lindsey

394 AQ4

He was employed for 27 years with Clark County, Nevada, and held positions 395 as Electrical Inspector, Electrical Plans Examiner, and Assistant Manager 396 of plan review. He is currently President of TLC Consulting Services, 397 AQ5 Las Vegas, NV, a consulting firm specializing in electrical codes and electrical 398 field research and investigation.

Mr. Lindsey is a member of the IEEE Industry Applications and the IEEE 400 AQ6 Power Engineering Societies, as well as the International Association of Elec- 401 AQ7 trical Inspectors. 


\section{AUTHOR QUERIES}

\section{AUTHOR PLEASE ANSWER ALL QUERIES}

AQ1 = The acronym "THHN" was defined as "Thermoplastic High Heat-resistant Nylon coated". Please check if correct.

AQ2 = Pls. provide page range in Ref. [7].

AQ3 = Please provide the educational background and photograph of author David Brender.

AQ4 = Please provide the educational background and photograph Travis L. Lindsey.

AQ5 = "TLCS, Inc." was changed to "TLC Consulting Services". Please check if correct.

AQ6 = The acronym "IAS" was defined as "Industry Applications Society". Please check if correct.

$\mathrm{AQ7}=$ The acronym "PES" was defined as "Power Engineering Society". Please check if correct.

AQ8 = The acronym "IAEI" was defined as "International Association of Electrical Inspectors". Please check if correct.

END OF ALL QUERIES 